REVIEW ARTICLE

\title{
Melatonin combats molecular terrorism at the mitochondrial level
}

\author{
Russel J. REITER ${ }^{1}$, Sergio D. PAREDES ${ }^{1}$, Ahmet KORKMAZ ${ }^{1}$, Mei-Jie JOU ${ }^{2}$, Dun-Xian TAN ${ }^{1}$ \\ 1 The University of Texas Health Science Center, Department of Cellular and Structural Biology, San Antonio, Texas, USA \\ ${ }^{2}$ Chang Gung University, Department of Physiology and Pharmacology, Kwei-Shan, Tao-Yuan, TAIWAN
}

ITX010208R02 • Received:23 July 2008 • Revised: 28 July 2008 • Accepted:29 July 2008 • Electronic Publication: November 2010

\begin{abstract}
The intracellular environmental is a hostile one. Free radicals and related oxygen and nitrogen-based oxidizing agents persistently pulverize and damage molecules in the vicinity of where they are formed. The mitochondria especially are subjected to frequent and abundant oxidative abuse. The carnage that is left in the wake of these oxygen and nitrogen-related reactants is referred to as oxidative damage or oxidative stress. When mitochondrial electron transport complex inhibitors are used, e.g., rotenone, 1-methyl1-phenyl-1,2,3,6-tetrahydropyridine, 3-nitropropionic acid or cyanide, pandemonium breaks loose within mitochondria as electron leakage leads to the generation of massive amounts of free radicals and related toxicants. The resulting oxidative stress initiates a series of events that leads to cellular apoptosis. To alleviate mitochondrial destruction and the associated cellular implosion, the cell has at its disposal a variety of free radical scavengers and antioxidants. Among these are melatonin and its metabolites. While melatonin stimulates several antioxidative enzymes it, as well as its metabolites (cyclic 3-hydroxymelatonin, $\mathrm{N}^{1}$-acetyl-N2-formyl-5-methoxykynuramine and $\mathrm{N}^{1}$-acetyl-5-methoxykynuramine), likewise effectively neutralize free radicals. The resulting cascade of reactions greatly magnifies melatonin's efficacy in reducing oxidative stress and apoptosis even in the presence of mitochondrial electron transport inhibitors. The actions of melatonin at the mitochondrial level are a consequence of melatonin and/or any of its metabolites. Thus, the molecular terrorism meted out by reactive oxygen and nitrogen species is held in check by melatonin and its derivatives.
\end{abstract}

KEY WORDS: melatonin; mitochondria; free radicals; oxidative stress; mitochondrial complex inhibitors

\section{Introduction}

Melatonin ( $N$-acetyl-5-methoxytryptamine) is an endogenously-produced molecule found throughout the animal kingdom from unicells to humans (Reiter, 1991a; Hardeland and Poeggeler, 2003). It is also present in plants (Hattori et al., 1995; Reiter et al., 2007; Kolar and MachacKova, 2005). Within multicellular organisms melatonin is generated in a wide variety of different tissues, although the pineal gland is the best known source of the indoleamine in vertebrates (Quay, 1974; Reiter, 1991b). Other major sites of melatonin production include the eye (Tosini et al., 2006; Itoh et al., 2007), brain (Jimenez-Jorge et al., 2007), gut (Bubenik and Pang, 2007), bone marrow (Tan et al., 1999a), skin (Slominski et al., 2005), immune cells (Carrillo-Vico et al., 2005) and others (Stefulj et al., 2001). In mammals, melatonin in the blood is primarily derived from the pineal gland (Quay, 1974; Reiter, 1991a). In the blood, melatonin levels exhibit

Correspondence address:

Prof. Russel J. Reiter, Ph.D.

Department of Cellular and Structural Biology,

University of Texas Health Science Center,

7703 Floyd Curl Drive, San Antonio, TX 78229-3900, USA

E-MAlL: reiter@uthscsa.edu a circadian rhythm with highest concentrations occurring during the dark period, coincident with maximal nocturnal melatonin production in the pineal gland (Reiter, 1987; 1991a). A melatonin rhythm similar to that in the blood also occurs in the cerebrospinal fluid (Skinner and Malpaux, 1999), saliva (Laakso et al., 1990) and at least one of its metabolites, 6-hydroxymelatonin, in the urine (Cavallo and Dolan, 1996).

Light-at-night quickly depresses pineal melatonin production via a pathway that involves a unique photopigment, melanopsin, in specialized photoreceptive retinal ganglion cells in the lateral eyes (Panda et al., 2005). The ability of light to inhibit nocturnal melatonin synthesis is both intensity (McIntytre et al., 1989) and wavelength (Brainard et al., 2001) dependent. As pineal melatonin synthesis falls due to nocturnal light exposure, likewise blood melatonin levels drop (Reiter, 1991a).

Besides light-at-night, a second major feature that reduces melatonin formation is age. In all species examined to date, increasing age is associated with a gradual waning of the nocturnal melatonin rhythm such that the elderly may be almost devoid of this important molecule (Reiter et al., 1980, 1981; Sack et al., 1986). Given the marked beneficial actions of melatonin at the cellular level, particularly in mitochondria (Acuna-Castroviejo et al., 2001; Leon et al., 
$2004,2005)$, the gradual reduction of melatonin throughout life may contribute to the persistent accumulation of oxidatively-modified molecules and worsening of a number of mitochondria-related disorders (Acuna-Castroviejo et al., 2002; DiMauro and Schon, 2003).

Melatonin is a ubiquitously-acting molecule which can function as an autocoid, paracoid, hormone, antioxidant and as a tissue factor (Tan et al., 2003). As such, this indoleamine mediates changes in seasonal reproduction in photoperiodic species (Reiter, 1980; Goldman, 1999), influences retinal physiology (Morgan and Boelan, 1996; Tosini, 2000), modulates the immune system (Guerrero and Reiter, 2002; Carrillo-Vico et al., 2006), inhibits the growth of a number of cancer cells (Blask et al., 2005; Leon-Blanco et al., 2003; Sanchez-Barcello et al., 2005), reduces oxidative stress (Siu et al., 2006; Maldonado et al., 2007; Jaworek et al., 2005), promotes sleep (Zisapel, 2007; Jan et al., 2007) and others.

Mechanistically, melatonin achieves its actions via a number of means. Many cells are equipped with membrane receptors which allow them to respond to the circadian melatonin message (Dubocovich and Markowska, 2005; Witt-Enderby et al., 2006). Melatonin binding sites (receptors) have also been found in the nuclei of many cells (Pozo et al., 2003; Coto-Montes et al., 2003). Whereas the signal transduction mechanisms involved in the actions of melatonin at the level of the membrane receptors have been reasonably well defined, information on these processes in terms of the nuclear binding sites remain, for the most part, enigmatic. Intracellularly, melatonin also binds to calmodulin allowing it to regulate several intracellular events, e.g., nitric oxide synthase (NOS) activity (Pozo et al., 1997; Benitez-King, 2006).

Additionally, melatonin has actions that do not require a receptor or formation of a complex with another molecule. This receptor-independent action, i.e., radical scavenging, only requires that melatonin be in the vicinity of a reactive oxygen or nitrogen specie when it is generated (Reiter, 1995; Tan et al., 2002; Hardeland et al., 2003a). Given that mitochondria are a major site of free radical production, it would obviously be advantageous if the concentrations of melatonin were also high within mitochondria. Whereas some preliminary data suggest that this organelle may contain melatonin concentrations that exceed levels in the blood or other portions of the cell (Martin et al., 2000), this evidence is certainly not unassailable.

\section{Mitochondria and free radical generation}

The inner mitochondrial membrane is unusually rich in proteins, half of which are involved in electron transport and in oxidative phosphorylation. The electron transport chain (ETC) which is coupled to oxidative phosphorylation provides cells with their major means of generation of its energy requirements (Scheffler, 1999). Up to 95\% of the ATP produced in aerobic cells is a result of mitochondrial oxidative phosphorylation. The activities of the ETC and oxidative phosphorylation must remain continuously active to ensure mitochondrial and cellular survival.
The majority of molecular oxygen $\left(\mathrm{O}_{2}\right)$ inhaled and eventually taken up by cells is processed in the mitochondrial ETC where it is converted to water following its four electron reduction. However, during this reductive process, partially reduced species of $\mathrm{O}_{2}$ are also produced including reactants that are reduced by one, two or three electrons, i.e., the superoxide anion $\left(\mathrm{O}_{2} \cdot-\right)$ and hydroxyl radical $(\bullet \mathrm{OH})$ and one non-radical product, hydrogen peroxide $\left(\mathrm{H}_{2} \mathrm{O}_{2}\right)$. Collectively, these agents are referred to as reactive oxygen species (ROS).

Free radicals generally have the capability to pair up their unpaired electron by abstracting one from another molecule (thereby damaging it). $\mathrm{O}_{2} \cdot-$ is not especially reactive in this regard. When formed, $\mathrm{O}_{2}{ }^{\cdot-}$ is usually quickly dismutated to $\mathrm{H}_{2} \mathrm{O}_{2}$ by cytosolic or mitochondrial superoxide dismutase (CuZnSOD and MnSOD), respectively. Since $\mathrm{H}_{2} \mathrm{O}_{2}$ is the immediate precursor of the highly damaging $\cdot \mathrm{OH}$, it is imperative that $\mathrm{H}_{2} \mathrm{O}_{2}$ be removed from the intramitochondrial environment as quickly as possible. The major enzyme that accomplishes this is glutathione peroxidase (GPx), which metabolizes $\mathrm{H}_{2} \mathrm{O}_{2}$ to water and $\mathrm{O}_{2}$; in this process GPx also converts reduced glutathione (GSH) to its oxidized metabolite (GSSG). Given the major importance of GSH in mitochondrial physiology, it is essential that GSSG be reduced back to GSH; this is accomplished by glutathione reductase (GRd) (Fernandez-Checa and Kaplowski, 2005).

The removal of $\mathrm{H}_{2} \mathrm{O}_{2}$ from the mitochondrial environment is never complete and, via the Fenton reaction, some damaging $\bullet \mathrm{OH}$ are always formed. Cellular organelles have no enzymatic means to remove $\cdot \mathrm{OH}$ so it must either be neutralized by a free radical scavenger or it mutilates a bystander molecule. This carnage occurs in the immediate vicinity of where the $\cdot \mathrm{OH}$ is formed because of its extremely rapid reaction rate; the damage is referred to as being site specific.

In addition to ROS, mitochondria also generate reactive nitrogen species (RNS); two of these are nitric oxide (NO) and the peroxynitrite anion $\left(\mathrm{ONOO}^{-}\right)$. Mitochondrial NO functions as a reversible antagonist of complex IV of the ETC by competing with $\mathrm{O}_{2}$ for its binding site. Usually tissue concentrations of $\mathrm{NO}$ and $\mathrm{O}_{2}$ are, respectively, in the ranges of $100-500 \mathrm{nM}$ and $10-30 \mu \mathrm{M}$. In these concentration ranges, NO causes roughly half maximal inhibition of mitochondrial respiration. Thus, NO is a physiological regulator of respiration and also of the rate of ATP synthesis (Brown, 1992). Elevation of NO levels higher than the concentrations mentioned above has the potential of inhibiting not only complex IV but also complexes I and III. In this eventuality, mitochondrial electron transfer reactions are compromised and electron leakage is exaggerated leading to increased formation of $\mathrm{O}_{2}{ }^{--}$and all down stream oxidants (Brown and Borutaite, 2004).

Additionally, NO readily couples with the $\mathrm{O}_{2}{ }^{\cdot-}$ to produce the non-radical species, the $\mathrm{ONOO}^{-}$, which irreversibly damages respiratory complexes (Cadenas et al., 1996). The toxicity of the $\mathrm{ONOO}^{-}$is probably on a par with that of the $\cdot \mathrm{OH}$ with the resultant damage potentially causing mitochondrial dysfunction and cell death (Brown, 1992).

A specific isoform of nitric oxide synthase (NOS) has been proposed to exist in mitochondria (mtNOS) (Ghafourifar 
and Cadenas, 2005). This constitutively expressed enzyme is believed to derive from a neuronal NOS isoform (Tatoyan and Giulivi, 1998). NO produced within mitochondria under normal conditions may serve a regulatory purpose, but when generated in excess, such as during inflammation (Escames et al., 2006), it may inhibit respiration and ATP production. Melatonin has been shown to inhibit NOS (Leon et al., 2004; 2005; Maldonado et al., 2007).

\section{Melatonin as a free radical scavenger and as an antioxidant}

Melatonin was discovered to be a free radical scavenger in 1993 (Tan et al., 1993). In this capacity, it is unexpectedly highly effective. Using the most definitive means of identifying a scavenger, i.e., a spin trapping agent and electron spin resonance spectroscopy, melatonin was documented to be a potent scavenger of the devastatingly reactive $\bullet \mathrm{OH}$. This seminal observation has been repeatedly confirmed in pure chemical systems in both in vitro and in vivo studies (Matuszek et al., 1997; Bromme et al., 2000; Li et al., 2002; Sofic et al., 2005; Valko et al., 2005; Fukutomi et al., 2006). Invariably, the degree of molecular damage that occurs as a consequence of $\cdot \mathrm{OH}$ generation is reduced in the presence of melatonin. This is obvious in the indoleamine's ability to protect against ionizing radiation, a process known to produce •OH in excess (Vijayalaxmi et al., 1999; Sever et al., 2004; Zhou et al., 2006).

Actually, melatonin scavenges two $\bullet \mathrm{OH}$ and, in the process, it is converted to cyclic 3-hydroxymelatonin (3-OHMEL). This latter product was identified by mass spectral analysis and carbon and proton-nuclear magnetic resonance (Tan et al., 1998; 1999b). Small amounts of cyclic 3-OHMEL are excreted in the urine (Ma et al., 2006); this also indicates that melatonin scavenges the $\cdot \mathrm{OH}$ in vivo. Cyclic 3-OHMEL is also formed during the interaction of melatonin with $\mathrm{ONOO}^{-}$(Zhang et al., 1999; Peyrot et al., 2002). Although cyclic 3-OHMEL is not commercially available, a method for its synthesis has been published (Sawicka et al., 2004) for those interested in using this molecule.

Like its parent molecule, cyclic 3-OHMEL is also a highly effective free radical scavenger and, in doing so, it is converted to $\mathrm{N}^{1}$-acetyl- $\mathrm{N}^{2}$-formyl-5-methoxykynuramine (AFMK) (Tan et al., 2000). This latter molecule is interesting and its existence has been known for more than 30 years after its discovery in the rat brain, where it is enzymatically formed by indoleamine 2,3-dioxygenase from melatonin (Hirata et al., 1974). For decades this was thought to be the exclusive means of AFMK formation in vivo. It is now known, however, that it may be non-enzymatically produced when melatonin scavenges $\mathrm{H}_{2} \mathrm{O}_{2}$ (Tan et al., 2000), as well as when it interacts with $\mathrm{O}_{2}{ }^{--}$(Hardeland et al., 1995), singlet oxygen $\left({ }^{1} \mathrm{O}_{2}\right)$ (de Almeida et al., 2003), or the $\mathrm{ONOO}^{-}$(Hardeland et al., 2003b). Finally, activated neutrophils and macrophages oxidize melatonin to AFMK (Silva et al., 2004). In plants as well as in animals, AFMK may be a major oxidation production of melatonin (Tan et al., 2007a). Collectively, the published findings suggest that AFMK is widely distributed in the animal and plant kingdoms. Like other melatonin catabolites, AFMK is found in the rat urine. Tan and colleagues (2007b) have speculated that AFMK may be a major derivative of melatonin.

AFMK has the ability to interact with the ABTS cation radical as well as with $\mathrm{ROS} / \mathrm{RNS}$ to form $\mathrm{N}^{1}$-acetyl-5methoxykynurmaine (AMK) (Rosen et al., 2006). AMK is then both a secondary or tertiary metabolite of melatonin. When AMK interacts with the ABTS cation radical (Than et al., 2006) or with $\mathrm{ONOO}^{-}$(Guenther et al., 2005) it forms products that may also be ROS and RNS scavengers.

This sequential scavenging of toxic reactants by melatonin and its metabolites is referred to as its antioxidative cascade and it is believed to be functional in vivo (Tan et al., 2007a). In this scheme it has been estimated that a single molecule of melatonin may neutralize up to ten toxic reactants. The oxidation reactions of melatonin as summarized in the foregoing paragraphs are summarized in Figure 1.

Supplementing the antioxidant capacity of melatonin is the ability of the indoleamine to promote the metabolism of toxic reactants to innocuous molecules. A number of antioxidative enzymes are important in limiting the oxidative burden of cells and organisms. As noted above, the major enzymes in this category are CuZnSOD, MnSOD, catalase (CAT), GPx and GRd. The SOD isoforms dismutate $\mathrm{O}_{2} \cdot-$ to $\mathrm{H}_{2} \mathrm{O}_{2}$ at different sites within the cell, i.e., CuZnSOD works in the cytosol while MnSOD is confined to mitochondria. While $\mathrm{H}_{2} \mathrm{O}_{2}$ is not very reactive it has a long half-life and can pass through cell membranes easily and, due to its conversion to the $\cdot \mathrm{OH}$ via the Fenton reaction, it can cause molecular damage at sites distant from its place of origin. To prevent this from happening, it is catalytically removed from the cellular environment by GPx and CAT. When $\mathrm{H}_{2} \mathrm{O}_{2}$ and/or other hydroperoxides are metabolized by GPx, GSH is likewise converted to its oxidized form, GSSG. Since it is important that a very high percentage of the glutathione in a cell be in the reduced form, GSSG is quickly metabolized back to GSH by the enzyme GRd.

It has been known for more than a decade that the activities of the antioxidative enzymes mentioned above are heightened in the presence of exogenously administered, pharmacological doses of melatonin (Barlow-Walden et al., 1995; Pablos et al., 1995). Furthermore, the physiological rise in circulating levels of melatonin at night reportedly enhances antioxidative enzyme activities (Pablos et al., 1998; Baydas et al., 2002). Besides seemingly inciting these enzymes, in some cases melatonin may merely protect these proteins from oxidative damage and thereby preserve their function.

Two recent reviews have considered the mechanisms involved in stimulation of antioxidative enzyme activities by melatonin (Rodriguez et al., 2004; Tomas-Zapico and Coto-Montes, 2005). While the direct free radical scavenging actions of melatonin described are obviously receptorindependent, there is a general consensus, although the evidence is not incontrovertible, that the induction of these enzymes by melatonin likely involves receptors. The proposed mechanisms include an interaction of melatonin with both membrane receptors and nuclear binding sites. The fact that melatonin (and its metabolites) functions in 


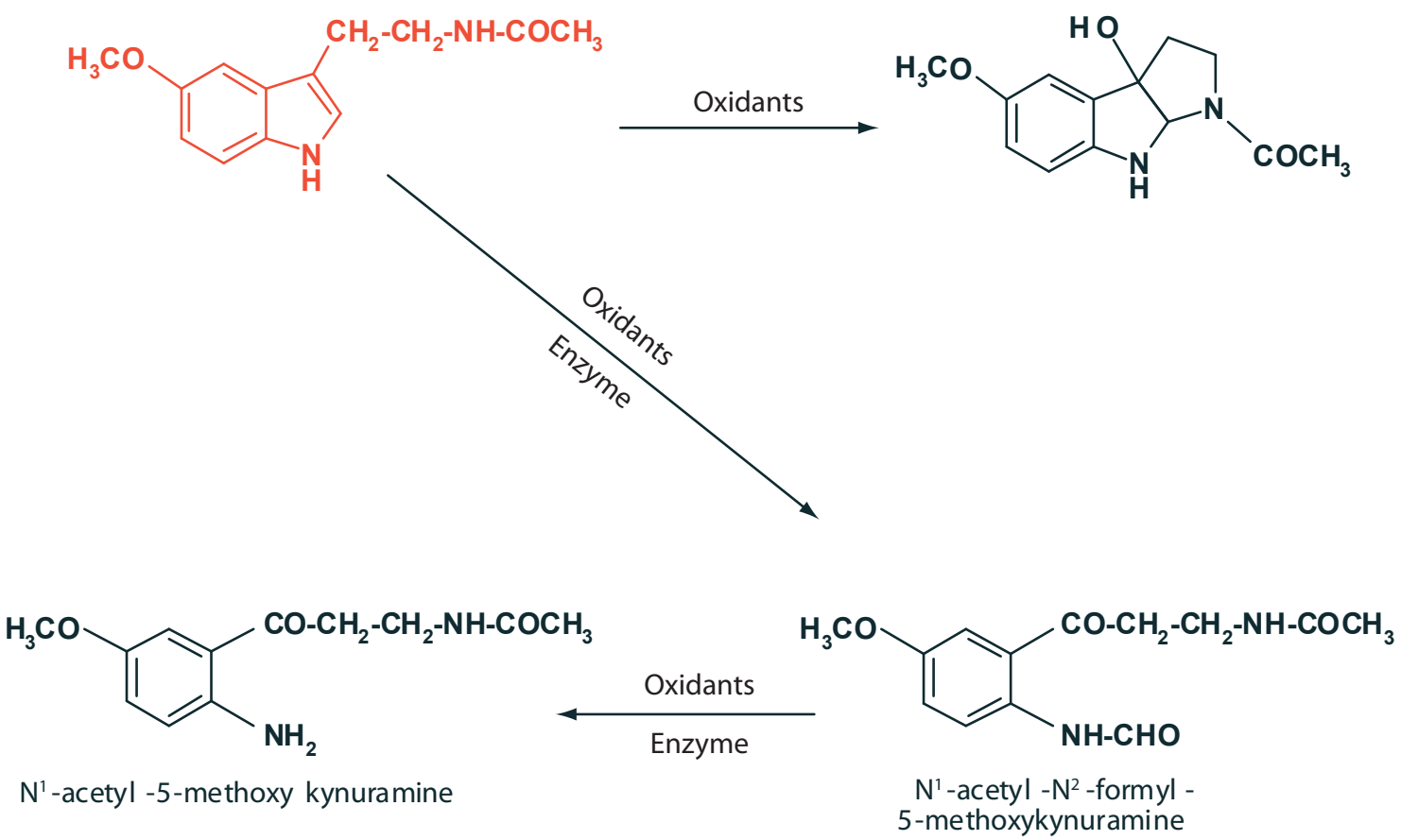

Figure 1. Melatonin oxidation and the products formed. While the parent molecule, melatonin, is a potent free radical scavenger, so are its metabolites. This scheme is referred to as the scavenger cascade of melatonin. It has been calculated that one molecule of melatonin may scavenge up to ten ROS/RNS. The figure is a composite of the findings published by Hardeland and colleagues (1995; 2003a, 2003b) and Tan et al. $(1993 ; 2000)$

the direct scavenging of ROS/RNS as well as activating enzymes which remove these potentially toxic agents from the intracellular environment greatly increases its ability to ward off molecular damage. Whereas melatonin acts as a direct free-radical scavenger in every cell, its stimulation of antioxidative enzymes would be limited to cells that possess receptors for the indoleamine, if the theory presented by Rodriguez et al. (2004) and Tomas-Zapico and CotoMontes (2005) is valid. Considering the very wide spread distribution of at least the membrane melatonin receptors (Dubocovich and Markowska, 2005), and also presumably the nuclear binding sites (Pozo et al., 2003; Coto-Montes et al., 2003; Carrillo-Vico et al., 2005), this action of melatonin may also occur essentially throughout the organism.

NOS, of which there are several isoforms, is the rate-limiting enzyme in the production of the gaseous neurotransmitter, NO. NO has both highly beneficial as well as negative consequences in organisms. As mentioned previously, this nitrogen-based reactant quickly couples with $\mathrm{O}_{2} \cdot-$ to form $\mathrm{ONOO}^{-}$which is highly reactive and destructive. Thus, NOS is often considered a pro-oxidative enzyme and its inhibition leads to reduced oxidative damage both at the cytosol and mitochondrial levels (Reiter et al., 2000; Acuna-Castroviejo et al., 2005). Melatonin reduces the activity of this enzyme when administered to experimental animals and at the same time it lessens free radical mutilation of essential molecules (Pozo et al., 1997;
Benitez-King, 2006; Escames et al., 2004; Leon et al., 2006). In some cases, the inhibition of NOS by melatonin may contribute significantly to the total antioxidative capacity of the indoleamine particularly at the mitochondrial level (Acuna-Castroviejo et al., 2005).

As already noted, keeping GSH levels high within cells is an important means of preserving the morphological and functional activities of molecules which would otherwise be degraded by free radicals and associated reactive products. In 1999, Urata and colleagues specifically tested whether melatonin would preserve intracellular GSH concentrations by enhancing its synthesis. They found, in fact, that melatonin stimulated the activity of the rate-limiting enzyme, $\gamma$-glutamylcysteine synthase $(\gamma$-GCS), in the production of this tripeptide antioxidant. Often, under elevated oxidative stress conditions, melatonin preserves intracellular GSH levels. This is not necessarily related to the ability of melatonin to stimulate $\gamma$-GCS since the indoleamine could preferentially scavenger free radicals and thereby preserve basal intracellular GSH concentrations. The stimulation of $\gamma$-GCS, as originally described by Urata et al. (1999), has been confirmed (Winiarska et al., 2006).

One final aspect should be considered when melatonin's ability to attenuate molecular impairment due to ROS/RNS is discussed. It is what Hardeland (2005) refers to as "radical avoidance". Melatonin has stimulatory effects particularly on complexes I and IV of the mitochondrial ETC; as such, 
the number of electrons that leak from the complexes is reduced and free radical generation is attenuated. Limited free radical generation would result in less harm to neighboring molecules.

This section briefly summarizes the multiple processes by which melatonin may restrict the destruction of molecules and organelles normally inflicted by ROS/RNS. Whereas these processes have all been documented in vivo, the significance of each in forestalling oxidative damage may be cell specific.

\section{Mitochondrial toxins: protection by melatonin}

Several drugs have been identified which are classified as mitochondrial poisons, i.e., they interfere with the transfer of electrons through the ETC. These drugs greatly exaggerate the escape of electrons into the mitochondrial intramembraneous space leading to a reduction of molecular oxygen and formation of radicals. Additionally, reduced oxidative phosphorylation precipitates a depletion of ATP (Beal, 1992). These changes cause elevated oxidative injury and an energy deficiency which, in the worst cases, leads to cellular and organismal death. The efficacy of melatonin in reducing the toxicity of some mitochondrial poisons has been examined.

\section{Rotenone}

Rotenone, a specific inhibitor of complex I of the mitochondrial ETC, causes the generation of an excessive number of free radicals. The damage inflicted by this drug is believed to be a consequence of the $\bullet \mathrm{OH}$ (Saravanan et al., 2005; 2006). Rotenone has been used to induce a neurodegenerative condition in animals that is reminiscent of Parkinsonism in humans since its action in complex inhibition is considered specific to dopamine-containing neurons. The classic antiParkinson drug, selegiline, protects against the neurodegenerative changes that are a consequence of rotenone due to its -OH scavenging actions (Saravanan et al., 2006).

Saravanan et al. (2007) stereotoxically infused rotenone $(6 \mu \mathrm{g}$ in $1 \mu \mathrm{L})$ unilaterally into the right substantia nigra (SN) of rats to induce a condition of hemiparkinsonism and tested the effect of melatonin $(10,20$ or $30 \mathrm{mg} / \mathrm{kg}$, i.p., 30 minutes before surgery and at 12 hour intervals after surgery for 4 days) in modulating the oxidative changes. At the termination of the study (5 days), measures of oxidative stress were compared in the infused and contralateral (non-rotenone treated) brain regions. On the rotenone-infused side of the brain nigral GSH levels were depressed by $49 \%$ while in the area of the terminals of the dopaminergic neurons (caudate nucleus, putamen; CNP), the reduction was $26 \%$. Melatonin at all doses significantly reduced the loss of GSH in the SN while the two larger doses also limited the depletion of GSH in the CNP. When the rotenone-infused SN was compared with its counterpart on the contralateral side of the brain (neural tissue obtained by micropunch), the drug increased both cytosolic SOD and CAT activities in the drugdamaged SN; the activities of both enzymes were further augmented after melatonin administration. The elevated enzyme activities after rotenone infusion were considered a compensatory response to the elevated oxidative stress. The additional rises induced by melatonin are consistent with its frequently-reported stimulation of antioxidative enzyme activities (Rodriguez et al., 2004; Tomas-Zapico and CotoMontes, 2005). That melatonin limited the loss of GSH in the rotenone-infused SN and associated CNP was explained by the fact that this indoleamine stimulates the rate limiting enzyme, $\gamma$-GCS, for the synthesis of this tripeptide antioxidant (Urata et al., 1999; Winiarska et al., 2006).

In an important ancillary study published in the same report, Saravanan and co-workers (2007) incubated neurally-derived submitochondrial particles (P2 fraction) with rotenone $(100 \mu \mathrm{M})$, salicylate $(0.7 \mathrm{mM})$ and different concentrations of melatonin $(0.1-1,000 \mu \mathrm{M})$ for 30 minutes. The formation of $\bullet \mathrm{OH}$ adducts of salicylate, i.e., 2,3-dihydroxybenzoic acid and 2,5-dihydroxybenzoic acid (2,3-DHBA and 2,5-DHBA, respectively) were estimated employing HPLC-electrochemistry. The addition of rotenone to the mitochondrial particles caused very large increases in 2,3-DHBA and 2,5-DHBA, indicative of highly elevated - $\mathrm{OH}$ generation, while melatonin significantly attenuated rotenone-mediated $\cdot \mathrm{OH}$ formation by the mitochondria. The ability of melatonin to reduce $\cdot \mathbf{O H}$-salicylate adducts was not unexpected considering that melatonin, as well as its metabolites, are highly efficient scavengers of not only the $\cdot \mathrm{OH}$ but any other radical or reactive species that may have been produced as a result of rotenone treatment (Tan $e t$ al., 1993; 2007b; Stasica et al., 1998, Hardeland, 2005).

Incubating isolated rat brain mitochondria with rotenone and $\mathrm{Ca}^{2+}$ induces marked oxidative damage to this organelle. The addition of melatonin to the purified mitochondria reduced the oxidative mutilation caused by the combination of rotenone and $\mathrm{Ca}^{2+}$ (Sousa and Castillo, 2005). Also, the addition of a $\mathrm{Ca}^{2+}$ ionophore (A23187), strongly potentiated rotenone-mediated death of pheochromocytoma (PC12) cells, a response attenuated by melatonin. Furthermore, in the presence of melatonin, free radicals were not detected to be released from PC12 cells co-exposed to rotenone plus the $\mathrm{Ca}^{2+}$ ionophore. Since melatonin did not change the concentration of $\mathrm{Ca}^{2+}$ nor did it prevent the inhibitory effect of rotenone on mitochondrial complex I, the authors concluded that the beneficial effects of melatonin on the mitochondria were primarily related to the antioxidative and free radical scavenging capacity of the indoleamine (Sousa and Castillo, 2005).

The fruit fly, Drosophila melanogaster, has been developed as a model for several neurodegenerative diseases, including Parkinsonism (Feany and Bender, 2000; Auluck et al., 2002). This model was used to examine the ability of melatonin to change the response of flies to rotenone treatment (Coulom and Birman, 2004). The mitochondrial toxin was fed to flies in the food they consumed; likewise, melatonin was administered via this route. Within a week, rotenone-only fed flies exhibited characteristic motor deficits and selective degeneration of the dopamine-containing neurons. When Drosophila were co-exposed to rotenone plus melatonin there was a markedly preserved motor behavior of the flies and, furthermore, melatonin was clearly 
superior to L-dopa in improving the score of the flies in the geotaxis test. When the number of dopamine-containing cells in the nervous system was compared in rotenonetreated flies with and without melatonin, it was obvious that the indoleamine had spared the dopaminergic neurons in many of the neuronal clusters from degeneration. In the rotenone-treated flies given melatonin, the number of dopaminergic neurons in some of the clusters was identical to those in non-treated control flies.

The difference between the relative efficacies of L-dopa and melatonin in reducing the toxicity of the mitochondrial complex I inhibitor in Drosophila is quite remarkable. While L-dopa attenuated some of the behavioral deficits associated with rotenone treatment, it failed to limit dopaminergic cell loss. Conversely, melatonin preserved normal behavior and reduced the destruction of the dopamine-containing neurons. The authors surmised that the high free radical scavenging and antioxidative activity of melatonin accounted for its protective actions against rotenone toxicity, although yet undefined mechanisms could not be excluded. On the basis of the findings, the authors suggested the use of melatonin by humans to prevent the neural oxidative damage that accompanies Parkinson disease (Coulom and Birman, 2004).

\section{1-Methyl-4-phenyl-1,2,3,6-tetrahydropyridine (MPTP)}

Roughly 30 years ago it was reported that young adults who unknowingly ingested MPTP developed severe neurological signs reminiscent of those seen in Parkinson disease (PD). It was immediately suspected that the drug caused damage to the dopaminergic cells of the substantia nigra which are the major neurons lost in individuals with idiopathic PD. When these individuals died and the brain was examined there was, in fact, a selective destruction of the mesencephalic dopamine-containing neurons. As tragic as these instances were, the identification of this destructive drug provided experimentalists with an agent that causes parkinson-like signs in animals. Use of MPTP has now become a model of examine the processes of $\mathrm{PD}$ as well as to investigate drugs that may modify the course of the disease.

When administered to animals, MPTP is taken up by astrocytes surrounding dopaminergic neurons and terminals where it is metabolized to 1-methyl-4-phenylpyridinium $\left(\mathrm{MPP}^{+}\right)$. The latter molecule is then released from the glial cells and is taken into dopaminergic nerves via the dopamine transporter. $\mathrm{MPP}^{+}$interferes with complex I of the mitochondrial ETC; this leads to cellular energy depletion and eventually to the death of dopaminergic cells.

Within a rather short interval after discovery of melatonin as an antioxidant, melatonin was used in an attempt to suppress the neural toxicity of MPTP. In this study, mice were injected with MPTP and were likewise given melatonin (Acuna-Castroviejo et al., 1997). Four hours later the brain of each mouse was recovered and the levels of lipid peroxidation products were found to be increased in the striatum and hippocampus as a result of MPTP administration; these increments were not observed in the mice treated with melatonin. More importantly, immunocytochemically-detected tyrosine hydroxylase activity in the dopaminergic nerve terminals in the striatum was lost as a result of the injection of MPTP; again this was prevented by melatonin. Although this study did not observe changes $\mathrm{n}$ the substantia nigra (likely due to the brief treatment period), the findings are consistent with a protective action of melatonin at the level of nigral dopaminergic neurons.

Shortly thereafter, a more thorough in vivo study that documented the ability of melatonin to limit damage to nigral dopaminergic neurons after $\mathrm{MPP}^{+}$administration was published by Jin and co-workers (1998). Using rats, they showed that the rise in lipid peroxidation products in the substantia nigra as well as the reduction in neuronal tyrosine hydroxylase activity (the enzyme that determines dopamine synthesis) did not occur in $\mathrm{MPP}^{+}$-treated animals when melatonin was given concurrently. Both acutely or chronically administered melatonin attenuated the damage inflicted by $\mathrm{MPP}^{+}$. In mice as well, the toxicity of MPTP at the level of the substantia nigra is reduced by melatonin administration (Ortiz et al., 2001). The endpoints in this study were the degree of nuclear DNA fragmentation and neuronal apoptosis.

One of the most compelling reports regarding the ability of melatonin to deflect the toxicity of MPTP at the level of the substantia nigra was published by Antolin and colleagues (Antolin et al., 2002). To promote a gradual reduction in the loss of dopamine-containing neurons in the substantia nigra, this group treated mice with a low daily dose of MPTP for 35 days; in half of the animals each injection of the complex I inhibitor was preceded by co-administration of melatonin. MPTP by itself caused a dramatic reduction in the number of Nissl-stained neurons and immunoreactive tyrosine hydroxylase-positive cells in the substantia nigra. In the mice given melatonin in conjunction with MPTP, the measured parameters were essentially indistinguishable from those of the control mice (Figure 2). These findings, along with others published soon thereafter (Khaldy et al., 2003; Chen et al., 2002) strongly support the idea that melatonin protects against mitochondrial complex I dysregulation induced by MPTP. That melatonin does not modify the conversion of MPTP to $\mathrm{MPP}^{+}$was shown by the observation that the indoleamine did not alter the level of monoamine oxidase B (Thomas and Mohanokumar, 2004); this enzyme is responsible for the metabolism of MPTP to $\mathrm{MPP}^{+}$

The most direct evidence that melatonin prevents the toxicity of $\mathrm{MPTP} / \mathrm{MPP}^{+}$at the level of the mitochondria was provided by Chen et al. (2005). This group measured mitochondrial DNA (mtDNA) damage as a result of MPTP administration to mice. They observed a rapid increase in immunoreactive 8-hydroxy-2-deoxyguanosine, a reliable marker of DNA damage, in mtDNA of the substantia nigra. Melatonin pre-injection, in a dose-response manner, reduced the damage. Likewise, using cultured SH-SY5Y cells Chen et al. (2005) also found melatonin was protective of mtDNA against $\mathrm{MPP}^{+}$toxicity and, moreover, they observed that $\mathrm{MPP}^{+}$time-dependently elevated mitochondrial free radical generation and a reduction in the mitochondrial membrane potential over a 24 hour period. Furthermore, 72 hours after $\mathrm{MPP}^{+}$exposure, $49 \%$ of the cells had undergone apoptosis. When cells were co-incubated with a combination of $\mathrm{MPP}^{+}$and melatonin, however, mitochondrial free 
radical generation was reduced, mitochondrial membrane potential did not collapse and cellular apoptosis was averted.

\section{3-Nitropropionic acid (3-NPA)}

3-NPA is a plant fungal toxin which inactivates mitochondrial succinate dehydrogenase (Coles et al., 1979). Succinate dehydrogenase (succinate-coenzyme $\mathrm{Q}$ reductase) is a key enzyme in complex II of the mitochondrial electron transport chain (Brandon et al., 2006). When 3-NPA is ingested by children who eat contaminated sugar cane, it causes basal ganglia lesions and marked dystonia as in Huntington's disease (HD) (Ludolph et al., 1991). Similarly, when this toxin is either administered systemically or if it is stereotaxically injected directly into the striatum of rodents, the neuropathological and neurobehavioral signs are similar to those seen in individuals with HD (Borlongan et al., 1995). Being a mitochondrial toxin, 3-NPA probably depletes cellular energy levels, which is also a deficit that likely occurs in HD (Beal, 1992).

To simulate HD, Tunez and colleagues (2004) used the mycotoxin to induce oxidative stress in the striatum and cerebral cortex of rats and tested whether melatonin would reduce the resulting damage caused by 3-NPA. 3-NPA was given at repeated intraperitoneally injected doses of $20 \mathrm{mg} / \mathrm{kg} \mathrm{BW}$ (in dimethylsulfoxide) for 4 days while melatonin ( $1 \mathrm{mg} / \mathrm{kg} \mathrm{BW}$ ) was given via the same route (before, during and 4 days after mycotoxin administration). In both striatal and cerebrocortical synaptosomes, a $65-70 \%$ reduction in succinate dehydrogenase activity was measured in response to 3-NPA only; melatonin coadministration returned the activity of this mitochondrial enzyme to near control levels. Associated with the loss in succinate dehydrogenase activity and a rise in free radical generation, the levels of lipid peroxidation products and protein carbonyls were elevated; both these consequences of mycotoxin administration were highly significantly reduced by melatonin. Whether melatonin actually prevented the drop in succinate dehydrogenase activity due to mycotoxin treatment or whether it merely restored enzyme activity after 3-NPA was discontinued could not be determined from this study.

A different approach was taken by Nam et al. (2005) who stereotoxically unilaterally injected 3-NPA into the striatum of rats while melatonin was given 30 minutes prior to and 60 minutes after mycotoxin administration and daily for 3 days thereafter. The use of 2,3,5-triphenyltetrazolium chloride staining revealed large lesions with extensive neuronal loss in the striata that were injected with 3-NPA. Moreover, the 3-NPA lesioned rats exhibited marked ipsilateral rotational behavior in response to apomorphine. The dopamine content of the damaged striata was also diminished while malondialdehyde (an index of the peroxidation of lipids) and oxidized protein levels were elevated in the area of the lesion. Melatonin given before and after the 3-NPA injection attenuated striatal neuronal loss, limited the degree of asymmetric rotational movement, preserved dopamine levels and reduced the amount of lipid and protein oxidation.

While the results of only two studies have been published related to the use of melatonin to ameliorate 3-NPA toxicity,

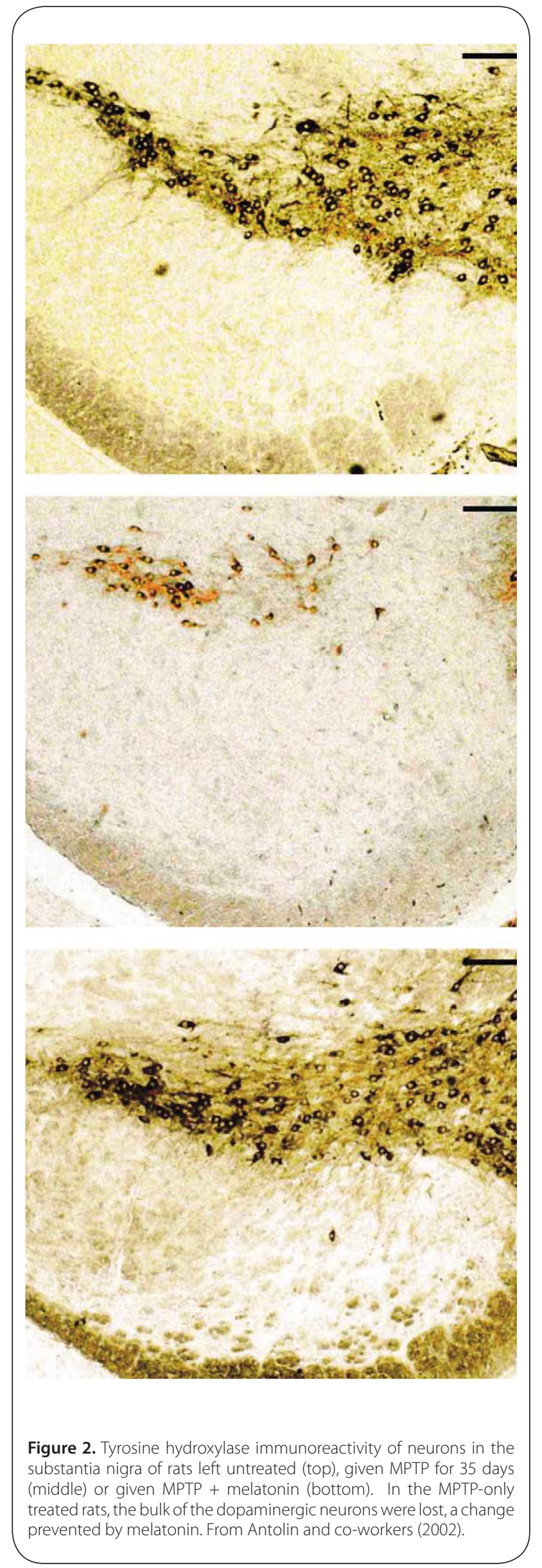


both reports showed conclusively that melatonin effectively counteracts the neuronal damage associated with succinate dehydrogenase poisoning. The findings are consistent with the idea that melatonin may have efficacy in the treatment of HD; this is supported by observations were melatonin was also found to be beneficial in another experimental model of this neurodegenerative condition, i.e., administration of quinolinic acid (Cabrera et al., 2000).

\section{Cyanide}

Cyanide is a potent inhibitor of cellular respiration by acting on cytochrome oxidase thereby blocking electron transport. This results in reduced oxidative phosphorylation, oxygen utilization and elevated free radical generation in the mitochondria.

Yamamoto and Tang (1996) performed a series of investigations to determine whether melatonin would reverse some of the sequalae of cyanide. In a dose-dependent manner, the subcutaneous administration of potassium cyanide $(6,8$, or $9 \mathrm{mg} / \mathrm{kg} \mathrm{BW}$ ) to mice caused severe tonic/clonic seizures and neural lipid peroxidation. Melatonin does-dependently reduced both the seizure incidence and lipid peroxidation in the cyanide-treated mice. The effective dose of cyanide to cause seizures in $50 \%$ of the mice, i.e., $\mathrm{ED}_{50}$, was elevated when melatonin was co-administered while the frequency of death in half of the animals at 24 hours $\left(\mathrm{LD}_{50}\right)$ was increased by melatonin treatment. The reduction in cyanide-mediated neural toxicity by melatonin was assumed to be related to the free radical scavenging activity of the indoleamine.

When cultured rat cortical neurons were exposed to potassium cyanide over a range of concentrations (0.01-1.0 mM) lactate dehydrogenase efflux, indicative of cellular damage, into the culture medium was observed. Melatonin significantly reduced escape of the enzyme from the neurons and preserved their morphology (Yamamoto and Tang, 1998). These researchers also showed, both in vitro and in vivo, that the damage to rat mtDNA by cyanide is also abolished by melatonin co-treatment (Yamamoto and Mohanan, 2002). The authors assumed that the mitochondrial dysfunction caused by cyanide initiated essentially uncontrolled free radical generation leading to oxidative mutilation of the neighboring mtDNA. This being the case, melatonin's ability to limit disfiguration of mtDNA was very likely a result of the high efficiency of the indoleamine as a scavenger of reactive oxygen and reactive nitrogen species.

\section{Apoptosis: prevention by melatonin}

One definitive endpoint of mitochondrial free radical generation is cellular apoptosis. Antioxidants that reduce the production of ROS/RNS at the mitochondrial level would be expected to limit cellular death. Using appropriate fluorescent probes, free radical production in mitochondria can be visualized along with many of the downstream events which culminate in the demise of the cell. With regard to melatonin's ability to act in mitochondria to alter the rate of free radical production, the most thorough studies are those of Jou and colleagues (Jou et al., 2002, 2004, 2007).
To initially observe intramitochondrial ROS, the fluorescent dye dihydrorhodamine-123, was used in astrocytes exposed to visible laser radiation. Using time-lapse confocal imaging of ROS production after subjecting astrocytes to laser irradiation, Jou et al. (2002) documented the dramatic increase in ROS over a 20 minutes period. The bulk of these reactants was clearly created within mitochondria. By imaging the changes at $30 \mathrm{sec}$ intervals for 20 minutes, the ROS were seen to accumulate rather slowly over the first 4 minutes of laser exposure with a much more rapid increase over the last 15 minutes. Concurrent phase contrast microscopy demonstrated the presence of other apoptosis-related cellular changes, e.g., cytoplasmic blebbing, nuclear condensation, etc. Moreover, melatonin and another antioxidant, vitamin E, largely attenuated laser irradiation-induced mitochondrial ROS formation and prevented apoptosis. In their most recent investigation, Jou and co-workers (2007) documented that, even in cells that have a common deletion of mitochondrial DNA and therefore generate an excess of free radicals, melatonin is still capable of reducing oxidative damage and preventing apoptosis.

In a second, more complete study, this group examined in detail many aspects of apoptosis and showed that melatonin also prevented death of cells caused by the oxidizing agent, $\mathrm{H}_{2} \mathrm{O}_{2}$ (Jou et al., 2004). With the aid of non-invasive mitochondrial-targeted fluorescent probes and time-lapse conventional, confocal, and multiphoton fluorescent imaging microscopy, the authors were able to show that melatonin effectively prevented endogenously-applied $\mathrm{H}_{2} \mathrm{O}_{2}$-induced mitochondrial swelling and apoptotic cell death. Moreover, melatonin reduced plasma membrane exposure of phosphatidyl serine, mitochondrial transition pore (MTP) opening, cytochrome c release, positive YOPRO-1 staining of the early apoptotic nuclei and DNA laddering. Besides inhibiting the apoptotic events initiated in astrocytes by $\mathrm{H}_{2} \mathrm{O}_{2}$, melatonin also reduced free radical formation and other degenerative cellular processes that resulted from the exposure of cells to either tert-butyl hydroperoxide or cumene hydroperoxide. Additionally, the protective effect of melatonin against these damaging agents was better than that provided by vitamin E (Jou et al., 2004). Figure 3 summarizes the processes involved in melatonin's actions in preventing free radicalmediated, mitochondrial-dependent cellular apoptosis.

The greater efficacy of melatonin in reducing observable free radical generation and apoptotic processes than vitamin $\mathrm{E}$ is a common observation. A number of studies have compared melatonin with classic antioxidants, e.g., glutathione, mannitol, vitamin $\mathrm{C}$, vitamin $\mathrm{E}$, etc., and invariably melatonin performs in a superior manner (Sofic et al., 2005; Qi et al., 2000; Martin et al., 2000).

According to Jou and colleagues (2004) the opening of the MTP follows free radical damage that accompanies oxidant exposure. However, other studies suggest that melatonin additionally, may have direct effects on the pore which prevent its opening and the escape of cytochrome $c$ (Andrabi et al., 2004).

Besides reducing free radical-mediated, mitochondrialdependent apoptosis, a process that does not require an interaction of melatonin with a receptor, melatonin may 

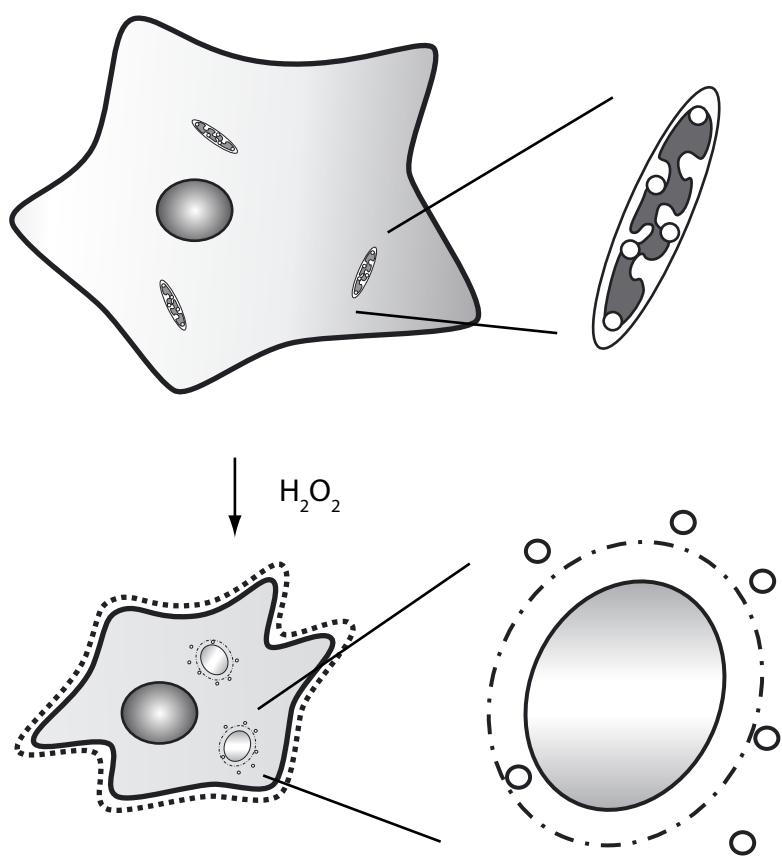

○

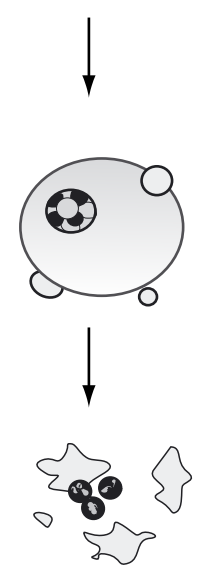

\section{Melatonin}

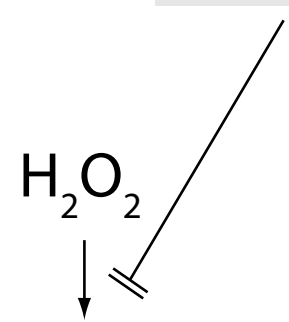

$[\mathrm{mROS}] \uparrow$

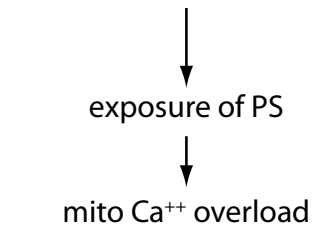

mito $\Delta \varphi$ depolarization

opening of the MPT pore

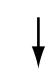

cytochrome c release

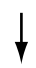

activation of caspase 3

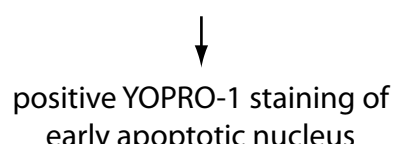

early apoptotic nucleus

condensation and karyorrhexis

of the nucleus

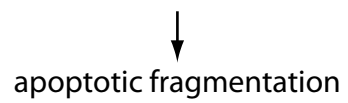

of nuclear DNA

Figure 3. This figure summarizes the findings as uncovered by Jou et al. (2004). By effectively scavenging reactive oxygen species generated within mitochondria, melatonin prevents the collapse of the mitochondrial membrane potential, opening of the mitochondrial transition pore (MTP) and the downstream events that lead to cellular apoptosis. Additionally, melatonin may have direct actions on the mitochondrial transition pore that are unrelated to its scavenging activity.

also have a receptor-mediated means of reducing the likelihood of apoptosis. Kilic et al. (2005a) examined the activation of a cytosolic signaling pathway after transient focal neural ischemia, which induces massive neuronal apoptosis, in mice. They used Western blots to analyze the phosphorylation of AKt, mitogen-activated protein (MAP) kinase/extracellular-regulated kinase (ERK)-1/2 and Jun kinase (JUN)-1/2 since they are crucial factors in reducing cellular death. On the basis of their results, however, Kilic and co-workers (2005a) concluded that phosphorylated ERK-1/2 and phosphorylated JNK-1/2 were not involved in melatonin's protection against neuronal loss after ischemia/ reperfusion injury to the brain. On the other hand, melatonin markedly upregulated phosphorylated AKt suggesting that the phosphoinositol-3 kinase/Akt pathway (PI-3K) is involved in mediating melatonin's protective actions in reducing neuronal loss due to apoptosis.

A follow-up study by the same group that melatonin acts to preserve the function of the PI-3 K/Akt pathway (Kilic et al., 2005b); this pathway has an inhibitory effect on mitochondrial injury and caspase activation (Yoshimoto et al., 2001; Friguls et al., 2002). As a result of the activation of the PI-3K pathway, phosphorylated Akt binds to Bad, a pro-apoptotic member of the Bcl-2 family; this impedes the translocation of Bad to the mitochondria. When phosphorylated Akt levels are lowered, Bad heterodimerizes with anti-apoptotic Bcl-2 members thereby reducing their efficacy in executing their cytoprotective actions (Abe et al., 
2004). Thus, melatonin's anti-apoptotic effects may be, at least in part, a result of its ability to preserve the activity of the PI-3K/Akt pathway. This explanation could also be used to define the findings of You et al. (2006) who reported the up-regulation of BcL- $\mathrm{X}_{\mathrm{L}}$ and the reduction in cytochrome $\mathrm{c}$ release from mitochondria by melatonin in the damaged newborn rat brain.

\section{Concluding remarks}

Mitochondria are the site of a large percentage of free radicals and related toxicants that are generated in cells. These reactive products cause damage to essential mitochondrial molecules which result in opening of the mitochondrial transition pore, release of cytochrome $\mathrm{c}$ and activation of the down stream events that culminate in free radicalmediated, mitochondrial-dependent apoptosis.

Since melatonin was discovered to be an indirect antioxidant and direct efficient free radical scavenger, its ability to reduce oxidative stress and to curtail cellular apoptosis has been repeatedly documented. It has also been shown that part of melatonin's ability to quell the oxidation of key molecules stems from its conversion to metabolites, i.e., cyclic 3-OHMEL, AFMK and AMK when it incapacitates free radicals and their related products.

The ability of melatonin to protect against oxygen- and nitrogen-based reactants is obvious in situations where toxins that inhibit the mitochondrial electron transport complexes are used. The mitochondrial poisons cause electron leakage with the resultant formation of large numbers of free radicals and consequentially molecular damage. This mutilation is inhibited by melatonin and its metabolites.

While melatonin readily resists mitochondrial oxidative damage and cellular apoptosis, there are many unanswered questions remaining. Some of the most noteworthy relate to the intramitochondrial concentrations of melatonin, the precise location of the indoleamine in relation to the complexes of the ETC, is it melatonin or a melatonin derivative that is the active agent in mitochondria and a definitive explanation for its high efficacy in preventing mitochondrial and cellular free radical-mediated destruction. Melatonin's very low toxicity combined with its high efficacy, however, portends its use in clinical medicine to treat conditions that are associated with elevated free radical damage, e.g., septic shock (Gitto et al., 2001), certain neurodegenerative conditions (Pappolla et al., 2003; Ishido, 2007), ischemia/ reperfusion injury (Reiter et al., 2005), ionizing radiation (Vijayalaxmi et al., 2004; Manda et al., 2007), and toxin (Xu et al., 2007; Matsura et al., 2006) and heavy metal (Qi et al., 2002; El-Sokkary et al., 2003) exposure, among others.

\section{REFERENCES}

Abe T, Takngi N, Nagano M, Furuza M, Takeo S (2004). Altered Bad localization and interaction between $\mathrm{Bad}$ and $\mathrm{BCl}-\mathrm{X}_{\perp}$ in the hippocampus after transient global ischemia. Brain Res 1009: 159-168

Acuna-Castroviejo D, Coto-Montes A, Gaia Monti M, Ortiz GG, Reiter RJ (1997). Melatonin is protective against MPTP-induced striated and hippocampal lesions. Life Sci 60, PL23-PL29.
Acuna-Castroviejo D, Escames G, Carozo A, Leon J, Khaldy H, Reiter RJ (2002). Melatonin, mitochondrial homeostasis and mitochondrial-related diseases. Curr Top Med Chem 2: 133-152.

Acuna-Castroviejo D, Martin M, Macias M, Escames G, Leon J, Khaldy H, Reiter RJ (2001). Melatonin, mitochondria, and cellular bioenergetics. J Pineal Res 30: $65-74$

Acuna-Castroviejo D, Escames G, Lopez LC, Hitos AB, Leon J (2005). Melatonin and nitric oxide: two required antagonists for mitochondrial homeostasis Endocrine 27: 159-168

Andrabi SA, Sayeed I, Siemen D, Wolf G, Horn TF (2004). Direct inhibition of the mitochondrial permeability transition pore: a possible mechanism responsible for anti-apoptotic effects of melatonin. FASEB J 18: 869-871.

Antolin I, Mayo JC, Sainz RM, de Brio ML, Herrera F, Martin V, Rodriguez C (2002). Protective effect of melatonin in a chronic experimental model of Parkinson's disease. Brain Res 943: 163-172.

Auluck PK, Chan HY, Trojanowski JQ, Lee VM, Bonini NM (2002). Chaperone suppression of alpha-synuclein toxicity in a Drosophila model in Parkinson's disease. Science 295: 685-688

Barlow-Walden LR, Reiter RJ, Abe M (1995). Melatonin stimulates brain glutathione peroxidase activity. Neurochem Int 26: 497-502.

Baydas G, Gursu MF, Yilmaz S (2002). Daily rhythm of glutathione peroxidase activity, lipid peroxidation and glutathione levels in tissues of pinealectomized rats. Neurosci Lett 323: 195-198.

Beal MF (1992). Does impairment of energy metabolism result in excitotoxic neuronal death in neurodegenerative illnesses? Ann Neuro/ 31: 119-130.

Benitez-King G (2006). Melatonin as a cytoskeletal modulator: implications for cell physiology and disease. J Pineal Res 40: 1-9.

Blask DE, Dauchy RT, Sauer LA (2005). Putting cancer to sleep at night: the neuroendocrine/circadian melatonin signal. Endocrine 27: 179-188.

Borlongan CV, Kautonzis TK, Freeman TB, Cahill DW, Sanberg PR (1995). Behavioral pathology induced by repeated systemic injections of 3-nitropropionic acid mimics the motoric symptoms of Huntington's disease. Brain Res 697:254-257.

Brainard GC, Hanifin JP, Rollag MD, Greeson J, Byrne B, Glickman G, Gerner E, Sanford B (2001). Human melatonin regulation in not mediated by the three cone photopic visual system. J Clin Endocrinol Metab 86: 433-436.

Brandon M, Baldi P, Wallace DC (2006). Mitochondrial mutations in cancer. Oncogene 25: 4647-4662

Bromme HJ, Morke W, Peschke D, Ebelt H, Peschke E (2000). Scavenging effect of melatonin on hydroxyl radicals generated by alloxan. J Pineal Res 29: 201-208.

Brown GC (1992). Control of respiration and ATP synthesis in mammalian mitochondria and cells. Biochem J 284: 1-13.

Brown GC, Borutaite V (2004). Inhibition of mitochondrial respiratory complex I by nitric oxide, peroxynitrite and S-nitrosothiols. Biochim Biophys Acta 1658 44-49.

Bubenik GA, Pang SF (1997). Melatonin levels in the gastrointestinal tissues of fish, amphibians and a reptile. Gen Comp Endocrinol 106: 415-419.

Cabrera J, Reiter RJ, Tan DX, Qi W, Sainz RM, Mayo JC, Garcia JJ, Kim SJ, El-Sokkary G (2000). Melatonin reduces oxidative neurotoxicity due to quinolinic acid: in vitro and in vivo findings. Neuropharmacology 39: 507-514.

Cadenas E, Poderoso JJ, Antunes F, Boveris A, Lizasoain I, Moro MA, Knowles RG, Darley-Usmar V, Moncada S (1996). Nitric oxide and peroxynitrite exert distinct effects on mitochondrial respiration which are differentially blocked by glutathione or glucose. Biochem J 314: 877-880

Carrillo-Vico A, Guerrero JM, Lardone PJ, Reiter RJ (2005). A review of the multiple actions of melatonin on the immune system. Endocrine 27: 189-200.

Carrillo-Vico A, Reiter RJ, Lardone PJ, Herrera JL, Fernandez-Montesinos R, Guerrero JM, Pozo D (2006). The modulatory role of melatonin on immune responsiveness. Curr Opin Investig Drugs 7: 423-431.

Cavallo A, Dolan LM (1996). 6-Hydroxymelatonin sulfate excretion in human puberty. J Pineal Res 21: 225-260.

Chen CJ, Gao YQ, Li XJ, Shen DH, Sun FY (2005). Melatonin protects against MPTP/MPP+-induced mitochondrial DNA oxidative damage in vivo and in vitro. J Pineal Res 39: 34-42.

Chen ST, Chuang Jl, Hong MH, Li El (2002). Melatonin attenuates MPP+-induced neurodegeneration and glutathione impairment in the nigro striatal dopaminergic pathway. J Pineal Res 32: 262-269.

Coles CJ, Edmondson DE, Singer TP (1979). Inactivation of succinate dehydrogenase by 3-nitropropionic acid. J Bio/ Chem 254: 5161-5167. 
Coto-Montes A, Tomas-Zapico C, Escames G, Leon J, Rodriguez-Colunga MJ, Tolivia D, Acuna-Castroviejo D (2003). Specific binding of melatonin to purified cell nuclei from mammary gland of Swiss mice: day-night variations and effect of continuous light. J Pineal Res 34: 297-301.

Coulom H, Birman S (2004). Chronic exposure to rotenone models: sporadic Parkinson's disease in Drosophila melanogaster. J Neurosci 24: 10993-10998.

de Almeida EA, Martinez GR, Klitzke CK, de Medeiros MH, Di Mascio P (2003). Oxidation of melatonin by singlet molecular oxygen produces $\mathrm{N}^{1}$-acetyl- $\mathrm{N}^{2}$ formyl-5-methoxykynuramine. J Pineal Res 35: 131-137.

Di Mauro S, Schon EA (2003). Mitochondrial respiratory-chain diseases. N Eng J Med 348: 2656-2668.

Dubocovich ML, Markowska M (2005). Functional MT1 and MT2 melatonin receptors in mammals. Endocrine 27: 101-110.

El-Sokkary G, Kamel ES, Reiter RJ (2003). Prophylactic effect of melatonin in reducing lead-induced neurotoxicity in the rat. Cell Molec Biol Lett 8: 461-470.

Escames G, Leon J, Lopez LC, Acuna-Castroviejo D (2004). Mechanisms in the NMDA receptor inhibition by melatonin in the rat brain striatum. J Neuroendocrino/ 16: 925-929.

Escames G, Lopez LC, Tapias V, Utrilla MP, Reiter RJ, Hitos AB, Leon J, Rodriguez MI, Acuna-Castroviejo D (2006). Melatonin counteracts inducible mitochondrial nitric oxide synthase-dependent mitochondrial dysfunction in skeletal muscle of septic mice. J Pineal Res 40: 71-78.

Feany MB, Bender WW (2000). A Drosophila model of Parkinson's disease. Nature 404: 394-398.

Fernandez-Checa JC, Kaplowski N (2005). Hepatic mitochondrial glutathione: transport and role in disease and toxicity. Toxicol Appl Pharmacol 204: 263-273.

Friguls B, Petegnief V, Justica C, Pallas M, Planas AM (2002). Activation of ERK and Akt signaling in focal cerebral ischemia: modulation of TGF-alpha and involvement of NMDA receptor. Neurobiol Aging 11: 443-456.

Fukutomi J, Fukado A, Fukado F, Hara M, Terada A, Yoshida M (2006). Scavenging activity of indole compounds against cisplatin-induced reactive oxygen species. Life Sci 80 : 254-257.

Ghafourifar P, Cadenas E (2005). Mitochondrial nitric oxide synthase. Trends Pharmacol Sci 26: 190-195.

Gitto E, Karbownik M, Reiter RJ, Tan DX, Cuzzocrea S, Chiurazzi P, Cardaro S, Corona G, Trimarchi G, Barberi I (2001). Effects of melatonin treatment in septic newborns. Pediat Res 50: 756-760.

Goldman BD (1999). The circadian timing system and reproduction in mammals. Steroids 64: 679-685.

Guenther AL, Schmidt SI, Laatsch H, Fotso S, Ness H, Ressmeyer AR, Poeggeler $B$, Hardeland R (2005). Reactions of the melatonin metabolite AMK ( $N^{1}$-acetyl5-methoxykynuramine) with reactive nitrogen species: formation of novel compounds, 3-acetoamidomethyl-6-methoxycinnolinone and 3-nitro-AMK. J Pineal Res 39: 251-260.

Guerrero JM, Reiter RJ (2002). Melatonin-immune system relationships. Curr Top Med Chem 2: 167-179.

Hardeland R (2005). Antioxidative protection by melatonin: multiplicity of mechanisms from radical detoxification to radical avoidance. Endocrine $\mathbf{2 7}$ : 119-130.

Hardeland R and Poeggeler B (2003). Non-vertebrate melatonin. J Pineal Res 34: 233-241.

Hardeland R, Balzer I, Poeggeler B, Fuhrberg B, Uria H, Behrmann G, Wolf R, Meyer TJ, Reiter RJ (1995). On the primary functions of melatonin in evolution: mediation of photoperiodic signals in a unicell, photoxidation, and scavenging of free radicals. J Pineal Res 18: 104-111.

Hardeland R, Coto-Montes A, Poeggeler B (2003a). Circadian rhythms, oxidative stress and antioxidative defense mechanisms. Chronobiol Int 20: 921-962.

Hardeland R, Poeggeler B, Niebergall R, Zelosko V (2003b). Oxidation of melatonin by carbonate radicals and chemiluminescence emitted during pyrrole ring cleavage. J Pineal Res 34: 69-74.

Hattori A, Migitaka H, ligo M, Itoh M, Yamamoto K, Ohtani-Kaneko R, Hara M, Suzuki T, Reiter RJ (1995). Identification of melatonin in plants and its effects on plasma melatonin levels and binding to melatonin receptors in vertebrates. Biochem Mol Biol Int 35: 627-634.

Hirata F, Hayaishi O, Tokuyama T, Seno S (1974). In vitro and in vivo formation of two new metabolites of melatonin. J Biol Chem 249: 1311-1313.

Ishido M (2007). Melatonin inhibits maneb-induced aggregation of a-synclein in rat pheochromocytoma cells. J Pineal Res 42: 125-130.
Itoh MT, Takahashi N, Abe M, Shimiza K (2007). Expression and cellular localization of melatonin-synthesizing enzymes in the rat lens. J Pineal Res 42: 92-96. Jan JE, Wasdell MB, Freeman RD, Bax M (2007). Evidence supporting the use of melatonin in short gestation infants. J Pineal Res 42: 22-26.

Jaworek J, Brzozowski T, Konturek SJ (2005). Melatonin as an organoprotector in the stomach and the pancreas. J Pineal Res 38: 73-83.

Jimenez-Jorge GM, Guerrero AJ, Jimenez-Caliam MC, Naranjo PJ, Lardone A, Carrillo-Vico C, Osuna C, Molinero P (2007). Evidence for melatonin synthesis in the rat brain during development. J Pineal Res 42: 240-246.

Jin BK, Shin DJ, Jeong MY, Gwag MR, Baik HW, Yoon KS, Cho YH, Joo WS, Kim YS, Baik HH (1998). Melatonin protects nigral dopaminergic neurons from 1-methyl-4-phenyl pyridinum. Neurosci Lett 245: 61-64.

Jou MJ, Jou SB, Chen HM, Lin CH, Peng TI (2002). Critical role of mitochondrial reactive oxygen species formation in visible laser irradiation-induced apoptosis in rat brain astrocytes (RBA-1). J Biomed Sci 9: 507-516.

Jou MJ, Peng TI, Reiter RJ, Jou SB, Wu HY, Wen ST (2004). Visualization of the antioxidant effects of melatonin at the mitochondrial level during oxidative stress-induced apoptosis of rat brain astrocytes. J Pineal Res 37: 55-70.

Jou MJ, Peng TI, Yu PZ, Jou SB, Reiter RJ, Chen JY, Wu HY, Chen CC, Hsu LF (2007). Melatonin protects against common deletion of mitochondrial DNAaugmented oxidative stress and apoptosis. J Pineal Res 43: 389-403.

Khaldy H, Escames G, Leon J, Bikjdaouene L, Acuna-Castroviejo D (2003). Synergistic effects of melatonin and deprenyl against MPTP-induced mitochondrial damage and DNA depletion. Neurobiol Aging 24: 491-500.

Kilic U, Kilic E, Reiter RJ, Bassetti CL, Herman DM (2005a). Signal transduction pathways involved in melatonin-induced neuroprotection after focal cerebral ischemia in mice. J Pineal Res 38: 67-71.

Kilic E, Kilic U, Reiter RJ, Bassetti CL, Hermann DM (2005b). Tissue-plasminogen activator-induced brain injury is reversed by melatonin: role of iNOS and Akt. J Pineal Res 39: 151-155.

Kolar J, Machackova I (2005). Melatonin in higher plants: occurrence and possible functions. J Pineal Res 39: 333-341.

Laakso ML, Porkka-Heiskanen T, Alila A, Steinberg D, Johansson G (1990). Correlation between salivary and serum melatonin: dependence on serum melatonin levels. J Pineal Res 9: 39-50.

Leon J, Acuna-Castroviejo D, Sainz RM, Mayo JC, Tan DX, Reiter RJ (2004). Melatonin and mitochondrial function. Life Sci 75: 765-790.

Leon J, Acuna-Castroviejo D, Escames G, Tan DX, Reiter RJ (2005). Melatonin mitigates mitochondrial malfunction. J Pineal Res 38: 1-9.

Leon J, Escames G, Rodriguez MI, Lopez LC, Tapias V, Entrena A, Camacho E, Carrion MD, Gallo MA, Espinosa A, Tan DX, Reiter RJ, Acuna-Castroviejo D (2006). Inhibition of neuronal nitric oxide synthase activity by $\mathrm{N}^{1}$-acetyl-5-methoxykynuramine, a brain metabolite of melatonin. J Neurochem 98: 2023-2033.

Leon-Blanco MM, Guerrero JM, Reiter RJ, Calvo JR, Pozo D (2003). Melatonin inhibits telomerase activity in the MCF-7 tumor cell line both in vivo and in vitro. J Pineal Res 35: 204-211.

Li XJ, Gu J, Lu SD, Sun FJ (2002). Melatonin attenuates MPTP-induced dopaminergic neuronal injury associated with scavenging hydroxyl radical. J Pineal Res 32: 42-52.

Ludolph AC, He F, Spencer PS, Hammerstad J, Sabri M (1991). 3-Nitropropionic acid - exogenous animal neurotoxin and possible human striatal toxin. Can $J$ Neuro/ Sci 18: 494-498.

Ma X, Idle JR, Krausz KW, Tan DX, Ceraulo L, Gonzalez FJ (2006). Urinary metabolites and antioxidant products of exogenous melatonin in the mouse. J Pineal Res 40: 343-349.

Maldonado MD, Murrillo-Cabezas F, Terron MP, Flores LJ, Tan DX, Manchester LC, Reiter RJ (2007). The potential of melatonin in reducing morbidity-mortality after craniocerebral trauma. J Pineal Res 42: 1-11.

Manda K, Ueno M, Anzai K (2007). AFMK, a melatonin metabolite, attenuates $X$-ray-induced oxidative damage to DNA, proteins and lipids in mice. J Pineal Res 42: 386-393.

Martin M, Macias M, Escames G, Leon J, Acuna-Castroviejo D (2000). Melatonin but not vitamins $C$ and $E$ maintains glutathione homeostasis in tert-butyl hydroperoxide induced mitochondrial oxidative stress. FASEB J 14: 1677-1679.

Matsura T, Nishida T, Togawa A, Horie S, Kusumoto C, Chata S, Nakada J, Ishibe Y, Yamada K, Ohta Y (2006). Mechanisms of protection by melatonin against acetaminophen-induced liver injury in mice. J Pineal Res 41: 211-219.

Matuszek Z, Reszka K, Chignell CF (1997). Reaction of melatonin and related indoles with hydroxyl radicals: ESR and spin trapping investigations. Free Radic Biol Med 23: 367-372. 
Mclntyre IM, Norman TR, Burrows GD, Armstrong SM (1989). Human melatonin response to light is intensity dependent. J Pineal Res 6: 149-156.

Morgan IG, Boelen MK (1996). A retinal dark-light switch: a review of the evidence. Vis Neurosci 13: 399-409.

Nam E, Lee SM, Koh SE, Joo WS, Maeng S, Im HI, Kim YS (2005). Melatonin protects against neuronal damage induced by 3 -nitropropanic acid in rat striatum. Brain Res 1046: 90-96.

Ortiz GG, Crespo-Lopez ME, Moran-Moguel C, Garcia JJ, Reiter RJ, Acuna-Castroviejo D (2001). Protective role of melatonin against MPTP-induced mouse brain cell DNA fragmentation and apoptosis in vivo. Neuroendocrinol Lett 22 : 101-108.

Pablos MI, Agapito MT, Gutierrez R (1995). Melatonin stimulates the activity of detoxifying enzyme glutathione peroxidase in several tissues of chicks. J Pineal Res 19: 111-115.

Pablos MI, Reiter RJ, Ortiz GG (1998). Rhythms of glutathione peroxidase and glutathione reductase in brain of chicks and their inhibition by light. Neurochem Int 32: 69-75.

Panda S, Nayak SK, Campo B, Walker JR, Hogenesch JB, Jegla T (2005). Illumination of melanopsin's signaling pathway. Science 307: 600-604.

Pappolla MA, Reiter RJ, Bryant-Thomas TK, Poeggeler B (2003). Oxidative mediated neurodegeneration in Alzheimer's disease: melatonin and related antioxidants as neuroprotective agents. Curr Med Chem 3: 233-243.

Peyrot F, Martin MT, Miguel J, Ducrocq C (2002). Reactivity of peroxynitrite with melatonin as a function of $\mathrm{pH}$ and $\mathrm{CO}_{2}$ content. Curr J Org Chem 321: 1-10.

Pozo D, Reiter RJ, Calvo JR, Guerrero JM (1997). Inhibition of cerebellar nitric oxide synthase and cyclic GMP production by melatonin via complex formation with calmodulin. J Cell Biochem 65: 430-442.

Pozo D, Garcia-Maurino S, Guerrero JM, Calvo RJ (2003). mRNA expression of nuclear receptor RZR/RORa, melatonin membrane receptor MT1, and hydroxyindole-O-methyltransferase in different populations of immune cells. $J$ Pineal Res 37: 48-54.

Qi W, Reiter RJ, Tan DX, Garcia JJ, Manchester LC, Karbownik M, Calvo JR (2000). Chromium (III)-induced 8-hydroxydeoxyguanosine in DNA and its reduction by antioxidants: comparative effects of melatonin, ascorbate and vitamin $\mathrm{E}$. Environ Health Persp 108: 2399-2402.

Qi W, Reiter RJ, Tan DX, Manchester LL, Siu AW, Garcia JJ (2002). Increased levels of oxidatively damaged DNA induced by chromium (III) and $\mathrm{H}_{2} \mathrm{O}_{2}$ : protection by melatonin and related molecules. J Pineal Res 29: 54-61.

Quay WB (1974). Pineal Chemistry in Cellular and Physiological Mechanisms. Springfield: Charles C. Thomas.

Reiter RJ (1980). The pineal and its hormones in the control of reproduction in mammals. Endocr Rev 1: 109-131.

Reiter RJ (1987). The melatonin message: duration versus coincidence hypotheses. Life Sci 40: 2119-2131.

Reiter RJ (1991a). Melatonin: cell biology of its synthesis and of its physiological interactions. Endocr Rev 12: 151-180.

Reiter RJ (1991b). Melatonin: the chemical expression of darkness. Mol Cell Endocrinol 79: C153-C158.

Reiter RJ (1995). Oxidative processes and antioxidative defense mechanisms in the aging brain. FASEB J 9: 526-533.

Reiter RJ, Richardson BA, Johnson LY, Ferguson BN, Dinh DT (1980). Pineal melatonin rhythm: reduction in aging Syrian hamsters. Science 210: 1372-1373.

Reiter RJ, Craft CM, Johnson JE, King Jr. TS, Richardson BA, Vaughan GM, Vaughan MK (1981). Age-associated reduction in nocturnal pineal melatonin levels in female rats. Endocrinology 109: 1295-1297.

Reiter RJ, Tan DX, Osuna C, Gitto E (2000). Actions of melatonin in the reduction of oxidative stress: a review. J Biomed Sci 7: 444-458.

Reiter RJ, Tan DX, Leon J, Kilic U, Kilic E (2005). When melatonin gets on your nerves: its beneficial effects in experimental models of stroke. Exp Biol Med 230: 104-17.

Reiter RJ, Tan DX, Manchester LC, Simopoulos AP, Maldonado MD, Flores LJ, Terron MP (2007). Melatonin in edible plants (phytomelatonin): identification, concentrations, bioavailability and proposed functions. World Rev Nutr Diet 97: $211-230$.

Rodriguez C, Mayo JC, Sainz RM, Antolin I, Herrera F, Martin V, Reiter RJ (2004). Regulation of antioxidant enzymes: a significant role for melatonin. J Pineal Res 36: 1-9.

Rosen J, Than NN, Koch D, Poeggeler B, Laatsch H, Hardeland R (2006). Interactions of melatonin and its metabolites with the ABTS cation radical: extension of the radical scavenger cascade and formation of a novel class of oxidation products, C 2 -substitued 3-indolinones. J Pineal Res 41: 374-381.
Sack RL, Lewy AJ, Erb DL, Vollmer WM, Singer CM (1986). Human melatonin production decreases with age. J Pineal Res 3: 379-388.

Sanchez-Barcello EJ, Cos S, Mediavilla D, Martinez-Compa C, Gonzalez A, Alonso-Gonzalez C (2005). Melatonin-estrogen interactions in breast cancer. J Pineal Res 38: 217-222.

Saravanan KS, Sindhu KM, Mohanakumar KP (2005). Acute intranigral infusion of rotenone in rats causes progressive biochemical lesions in the striatum similar to Parkinson's disease. Brain Res 1049: 157-155.

Saravanan KS, Sindhu KM, Mohanakumar KP (2007). Melatonin protects against rotenone-induced oxidative stress in a hemiparkinsonian rat model. J Pineal Res 42: 247-253.

Saravanan KS, Sindhu KM, Senthikumar KS, Mohanakumar KP (2006). L-Dephenyl protects against rotenone-induced, oxidative stress-mediated dopaminergic neurodegeneration in rats. Neurochem Int 49: 28-40.

Sawicka A, Reiter RJ, Tan DX, Wojtasievoicz K, Leneniewska A, Mavrin JK, Balachut D, Czarnocki Z (2004). The synthesis and the structure elucidation of $\mathrm{N}, \mathrm{O}$-diacetyl erivative of cyclic 3-hydroxymelatonin. Central Eur J Chem $\mathbf{2}$ 425-433.

Scheffler IE (1999). Mitochondria. New York: Wiley-Liss.

Sever G, Atasoy BM, Ersoy Y, Arbak S, Sengoz M, Yegen BC (2004). Melatonin protects against ionizing radiation-induced oxidative damage to corpus cavernosum and urinary bladder in rats. J Pineal Res 37: 241-246.

Silva SO, Rodriguez MR, Carvalho SR, Catalani LA, Campa A, Ximenes VF (2004). Oxidation of melatonin and its catabolites, $\mathrm{N}^{1}$-acetyl-N2-formyl-5-methoxykynuramine and $\mathrm{N}^{1}$-acetyl-5-methoxykynuramine, by activated leukocytes. J Pineal Res 37: 171-175.

Siu AW, Maldonado MD, Sanchez-Hidalgo M, Tan DX, Reiter RJ (2006). Protective effects of melatonin in experimental free radical-related ocular diseases. J Pineal Res 40: 101-109.

Skinner DC, Malpaux B (1999). High melatonin concentrations in third ventricular cerebrospinal fluid are not due to Galen vein blood recirculating through the choroid plexus. Endocrinology 140: 4399-4405.

Slominski A, Wortsman J, Tobin DJ (2005). The cutaneous serotoninergic/melatoninergic system: securing a place under the sun. FASEB J 19: 176-194.

Sofic E, Rimpapa Z, Jundorovic Z, Sapcanin A, Tahiorovic I, Rustembegovic A Cao G (2005). Antioxidant capacity of neurohormone melatonin. J Neural Transm 112: 349-358.

Sousa SC, Castillo RF (2005). Protective effect of melatonin on rotenone plus $\mathrm{Ca}^{2+-i n d u c e d}$ mitochondrial oxidative stress and PC12 cell death. Antioxid Redox Signal 9: 1110-1116.

Stasica P, Ulanski P, Rosiak JM (1998). Melatonin as a hydroxyl radical scavenger J Pineal Res 25: 65-66.

Stefulj J, Hortner M, Shosh M, Schavenstein K, Rinner I, Wolfler A, Semmler J, Liebmann PM (2001). Gene expression of key enzymes of melatonin synthesis of extrapineal tissues of the rat. J Pineal Res 30: 243-247.

Tan DX, Chen LD, Poeggeler B, Manchester LC, Reiter RJ (1993). Melatonin: a potent, endogenous hydroxyl radical scavenger. Endocr $J$ 1: 57-60.

Tan DX, Manchester LC, Reiter JR, Plummer BF, Hardes LJ, Weintraub ST, Vijayalaxmi, Shepherd AM (1998). A novel melatonin metabolite, cyclic 3-hydroxymelatonin, a biomarker of in vivo hydroxyl radical generation. Biochem Biophys Res Commun 30: 614-620.

Tan DX, Manchester CC, Reiter RJ, Qi WB, Zhang M, Weintraub ST, Cabrera J, Sainz RM, Mayo JC (1999a). Identification of highly elevated levels of melatonin in bone marrow: its origin and significance. Biochim Biophys Acto 1472: 206-214.

Tan DX, Manchester LC, Reiter RJ, Plummer BF (1999b). Cyclic 3-hydroxymelatonin: a melatonin metabolite generated as a result of hydroxyl radical scavenging. Biol Signals Recept 8: 70-74.

Tan DX, Manchester LC, Reiter RJ, Plummer BF, Limson J, Weintraub ST, Qi W (2000). Melatonin directly scavenges hydrogen peroxide: a potentially new metabolic pathway of melatonin biotransformation. Free Radic Biol Med 29 1177-1185.

Tan DX, Reiter RJ, Manchester LC, Yan MT, El-Sawi M, Sainz RM, Mayo JC, Kohen R, Allegra M, Hardeland R (2002). Chemical and physical properties and potential mechanisms: melatonin as a broad spectrum antioxidant and free radical scavenger. Curr Top Med Chem 2: 181-182.

Tan DX, Manchester LC, Hardeland R, Lopez-Burillo S, Mayo JC, Sainz RM, Reiter RJ (2003). Melatonin: a hormone, a tissue factor, an autocoid, a paracoid, and an antioxidant vitamin. J Pineal Res 34: 75-78. 
Tan DX, Manchester LC, Di Mascio P, Martinez CR, Prado FM, Reiter RJ (2007a). Novel rhythms of $\mathrm{N}^{1}$-acetyl-N2-formyl-5-methoxykynuramine and its precursor melatonin in water hyacinth: importance for phytoremediation. FASEB $J$ 21: $1724-1729$.

Tan DX, Manchester LC, Terron MP, Flores LJ, Reiter RJ (2007b). One molecule, many derivatives: a never-ending interaction of melatonin with reactive oxygen and reactive-nitrogen species? J Pineal Res 42: 28-42.

Tatoyan A, Giulivi C (1998). Purification and characterization of nitric oxide synthase from rat liver mitochondria. J Biol Chem 273: 11044-11048.

Than NN, Heer C, Laatsch H, Hardeland R (2006). Reaction of the melatonin metabolite N1-acetyl-5-methoxykynuramine (AMK) with the ABTS cation radical: identification of new oxidation products. Redox Rep 11: 15-24.

Thomas B, Mohanokumar KP (2004). Melatonin protects against oxidative stress caused by 1-methyl-4-phenyl-1,2,3,6-tetrahydropyridine in mouse nigrostriatum. J Pineal Res 36: 25-32.

Tomas-ZapicoC,Coto-Montes A(2005).Aproposedmechanismtoexplainthestimulatory effect of melatonin on antioxidative enzymes. J Pineal Res 39: 99-104.

Tosini G (2000). Melatonin circadian rhythm in the retina of mammals. Chronobiol Int 17: 599-612.

Tosini G, Chaurasia SS, luvone PM (2006). Regulation of arylakylamine $\mathrm{N}$-acetyltransferase (AANAT) in the retina. Chronobiol Int 23: 381-391.

Tunez I, Montilla P, del Carmen Munoz M, Feijoo M, Salcedo M (2004). Protective effect of melatonin on 3-nitropropionic acid-induced oxidative stress in synaptosomes in an animal model in Huntington's disease. J Pineal Res 37: 252-256.

Urata Y, Honma S, Goto S, Todoroki S, lida T, Cho S, Honma K, Kondo T (1999). Melatonin induces gamma-glutamylcysteine synthase mediated by activator protein-1 in human vascular endothelial cells. Free Radic Biol Med 27: 838-847.

Valko M, Morris H, Cronin MT (2005). Metals, toxicity and oxidative stress. Curr Med Chem 12: 1161-1208.

Vijayalaxmi, Meltz ML, Reiter RJ, Herman TS (1999). Melatonin and protection from damage in blood and bone marrow: whole body radiation studies in mice. J Pineal Res 27: 221-225.
Vijayalaxmi, Reiter RJ, Tan DX, Herman TS, Thomas CR Jr (2004). Melatonin as a radioprotective agent: a review. J Radiat Oncol Biol Physics 59: 639-653.

Winiarska K, Fraczyk T, Melinska D, Drozak J, Bryla J (2006). Melatonin attenuates diabetes-induced oxidative stress in rabbits. J Pineal Res 40: 168-176.

Witt-Enderby PA, Radio NM, Doctor JS, David VL (2006). Therapeutic treatments potentially mediated by melatonin receptors: potential clinical uses in the prevention of osteoporosis, cancer and as an adjuvant therapy. J Pineal Res 41: 297-305.

Xu J, Sun S, Wei W, Fu J, Qi W, Manchester LC, Tan DX, Reiter RJ (2007). Melatonin reduces mortality and oxidatively mediated hepatic and renal damage due to diquat treatment. J Pineal Res 42: 166-171.

Yamamoto H, Mohanan PV (2002). Melatonin attenuates brain mitochondria DNA damage induced by potassium cyanide in vivo and in vitro. Toxicology 179: 29-36.

Yamamoto H, Tang HW (1996). Preventive effect of melatonin against cyanideinduced seizures and lipid peroxidation in mice. Neurosci Lett 207: 89-92.

Yamamoto H, Tang H (1998). Effects of 2-amino-7-phosphonohepatanoic acid, melatonin or NG-nitro-L-arginine on cyanide or N-methyl-D-aspartate induced neurotoxicity in rat cortical cells. Toxicol Lett 94: 13-18.

Yoshimoto T, Uchino H, He QP, Li PA, Siesjo BK (2001). Cyclosporin A, but not FK506, prevents the downregulation of phosphorylated Akt after transient focal cerebral ischemia in the rat. Brain Res 899: 148-158.

You JH, Carter LB, Reiter RJ, Jevtovic-Todorovic V (2006). Melatonin reduces the severity of anesthesia-induced apoptotic neurodegeneration in the developing rat brain. Neurobiol Dis 21: 522-530.

Zhang H, Squadrito GL, Uppa R, Pryor WA (1999). Reaction of peroxynitrite with melatonin: a mechanistic study. Chem Res Toxico/ 12: 526-534

Zhou G, Kawata T, Furusawa Y, Aoki M, Hirayama R, Ando K, Ito H (2006). Protective effects of melatonin against low and high-LET irradiation. J Radiat Res 47: $175-181$

Zisapel N (2007). Sleep and sleep disturbances: biological basis and clinical implications. Cell Mol Life Sci 64: 1174-1186. 